\title{
A Comparison of Skin Thickness Data from Ultrasonography with Literature Data Obtained via Histology and Magnetic Resonance Imaging: Posterior Neck, Lumbar Back, Lateral Epicondyle, and Posterior Knee
}

\author{
${ }^{1}$ Private practice, Chêne-Bougeries, Switzerland \\ ${ }^{2}$ Medlmage, Private RX institute, Geneva, Switzerland \\ ${ }^{3}$ Private practice, Geneva, Switzerland \\ ${ }^{4}$ Medical center, Grand-Saconnex, Switzerland
}

Patrick Micheels ${ }^{1, *}$, Stéphanie Besse ${ }^{2}$, Badwi Elias ${ }^{3}$, and Sandor Viski

*Corresponding author: Patrick Micheels, Private practice, Chêne-Bougeries, Switzerland Tel: +41 2234711 13; E-mail: patrickscab@bluewin.ch

Received: 20 May, 2020 | Accepted: 17 Jun, 2020 | Published: 24 Jun, 2020

Citation: Micheels P, Besse S, Elias B, Viski S (2020) A Comparison of Skin Thickness Data from Ultrasonography with Literature Data Obtained via Histology and Magnetic Resonance Imaging: Posterior Neck, Lumbar Back, Lateral Epicondyle, and Posterior Knee. J Clin Cosmet Dermatol 4(3): dx.doi.org/10.16966/2576-2826.153

Copyright: (C) 2020 Micheels P, et al. This is an open-access article distributed under the terms of the Creative Commons Attribution License, which permits unrestricted use, distribution, and reproduction in any medium, provided the original author and source are credited.

\begin{abstract}
Introduction: Over many years now, our team has been convinced that the injection depths indicated by authors in published studies on intradermal injection therapy or in the esthetic field are incorrect. This paper sought to compare skin thickness data derived from Ultrasonography with literature data obtained via histological examination and magnetic resonance imaging.

Patients and Methods: Skin layer thickness measurements were performed on healthy subjects using ultrasound imaging technology. In each case, the ultrasound transducer was placed on the posterior neck, lumbar back, lateral epicondyle, and posterior knee. These data were compared with skin layer thickness measurements obtained via histological examination and magnetic resonance imaging.

Results: Overall, 80 healthy subjects were classified according to gender and age: 10 females and 10 males pertaining to each of the following age groups: $35-45,46-55,56-65$, and $>66$ years. The comparative histological data concerned 140 skin residues, with a descriptive histological analysis of each cutaneous area; the comparative MRI data concerned 36 healthy subjects and 31, with only calf and scapula data considered, respectively. Our study results reveal that the skin thickness measurements slightly vary by some microns (or micrometers), depending on the technology used. However, irrespective of the technology applied, there is a key observation that can be drawn based on our study data: The skin is very thin. Indeed, the skin is thinner than initially anticipated by several eminent authors, teachers, or educators. Accordingly, the skin appears particularly delicate and fragile in the case when intradermal injections are made.
\end{abstract}

Conclusion: Based on this study's findings, it seems warranted that the injection techniques and definitions herein be thoroughly reviewed, with several suggestions proposed in this paper.

Keywords: Mesotherapy; Intradermal therapy; Injection depth; Needle penetration angle; Intraepidermal injection; Intradermal injection

\section{Introduction}

Mesotherapy, which is now called "Intradermal Injection Therapy" (IDT), was first described by the French physician Dr. Pistor M [1]. IDT mainly consists of intradermal injections of trophic substances, such as vitamins, medications (like anti-inflammatory substances, myorelaxants, or vasodilatators), minerals, hormones and enzymes $[2,3]$. While the initial indications of IDT were primarily related to general practice, primarily concerning the musculoskeletal system [4], they have meanwhile been enlarged to a variety of cosmetic conditions, such as skin rejuvenation and resurfacing.

Indeed, one of mesotherapy's major advantages has been and still is that a local pharmacological effect can be obtained with lower doses of bioactive substances, especially when the injection area is close to the pathological site. To cite a concrete example, in lower back pain, IDT may be associated with clinical benefits, when given either alone or in combination with other therapies like physiotherapy or kinesitherapy, although other therapies are ineffective or cannot be used in sufficiently high doses. In sports medicine, IDT can be of benefit to players with soft tissue injuries, who naturally aim to return to play at the earliest possible time [4]. Moreover, intradermal injection of bioactive agents and IDT may thus prove dose-sparing [5].

Whether for IDT training, esthetic medicine designed to correct wrinkles and folds, or general medicine for the treatment of local pain, 
in all these cases, precise instructions have to be followed concerning the different depths to which the bioactive products are injected. In esthetic medicine, where IDT is primarily used to prevent skin aging, the instructions for use specify that the substances are respectively injected into the upper, middle, or lower dermis, and at times as deep as the subcutaneous fatty tissue or even the supraperiostal level. Notably, in the medical literature, these skin layers were generally referred to as superficial, mid, and deep dermis. In the IDT setting, a clear-cut distinction is made between four different injection types: 1) epidermal injection, which is a mild brush of the stratum corneum rather than a true injection; 2) superficial intradermal injection, which is also referred to as nappage or picotage and is considered the gold standard of intradermal therapy; 3) deep intradermal injection, which is also referred to as a "point-by-point" technique; 4) dermohypodermal injection, which is an injection placed at a depth of 4-6 $\mathrm{mm}$, possibly up to $10 \mathrm{~mm}$. This latter injection type (and depth) has been heralded by Thierree RA, et al. in a most interesting research focused on microcirculation, mesotherapy and thermography [6].

For many years now, we have been certain that the injection depths reported by authors in several publications focused on IDT or esthetic medicine are rather approximate, or even completely inaccurate. So far, we have published several papers dealing with injection depths for wrinkle filling therapies [7-9]. In a recently accepted article for publication in June 2020, we primarily focused our UltraSound (US) research on the cheek, neck, and décolleté. These are key areas targeted by esthetic medicine, particularly for correcting loss of facial volume, as well as for skin rejuvenation, in the form of Meso Lift, Meso Glow, or other "skin boosters". In the current paper, the focus is set on other body parts, which are of major interest in general medicine and standard IDT. These areas are as follows: posterior neck at the cervical spine C5-C6, lumbar back at the lumbar spine L4-L5, lateral epicondyle, and posterior knee at the fibular head. Figure 1 provides an overview of the different US-studied sites.

The same questions as those addressed in previously published papers are raised here, though they concern body parts that particularly concern general medicine and IDT. Do the technical terms employed to define the injection technique actually correspond to the injection depth attained when the injection is actually carried out? It is against this background that the current study was designed and implemented. For this report, we sought to compare data collected by our research team using US technology with those retrieved from scientific literature and derived from either skin biopsies or via Magnetic Resonance Imaging (MRI) from different authors.

\section{Materials and Methods}

\section{Subjects}

Initially, US measurements were performed in two subjects: the first, a 66-year-old Caucasian woman; the second, a 61-year-old Caucasian man, both with Fitzpatrick Type IV skin [10]. Next, the measurements were further refined and involved 10 female and 10 male subjects pertaining to each of the following age groups: $35-45$, $46-55,56-65$, and $>66$ years, resulting in 80 subjects overall. The initial two subjects were retested in this part of our observation while using the second US device.

For each area, we have calculated the mean thickness of the different skin layers for the different age groups, each of which included 10 subjects of both genders, with injections made on both the right and left sides. Accordingly, for each skin layer and in each age group, 40 measurements have been made available. These latter constitute the basis for our mean measured thickness of the different skin layers.
Compared to our comparators, we have thus the same amount of measurements, or even slightly more.

\section{Ultrasonography}

Concerning the equipment applied, for the two first study subjects, the authors collaborated with the Medimage Radiology Institute in Geneva, Switzerland, using a Samsung RS80A with a Prestige US machine and Meditron $4-18-\mathrm{MHz}$ high-resolution transducer (Meditron, Gland, Switzerland). Secondarily, for the 80 patients, a LOGIQ e imaging engine and $17 \mathrm{MHz}$ L8-18i RS linear transducer (both from GE Medical Systems, Opfikon, Switzerland) was employed.

For the US measurements, subjects were required to attend, only once, the Magellan center, Geneva, Switzerland. Prior to entry, all subjects received verbal and written information about the study's procedures; all delivered informed written consent, prior to study enrollment. They were given a 15-day period to confirm their effective study participation, in line with the Declaration of Helsinki principles. The signed consent forms additionally provided agreement for photography and US skin data collection for the study purpose. Due to the different time schedules and the required availability of both study participants and investigating physicians, the trial was conducted over a 15-month period, from October 2018 to December 2019.

Abundant water-based gel was applied between US probe and skin in order to ensure smooth transmission of ultrasound waves, as illustrated in figure 1 and 2 .

Next, the transducer was systematically placed on the subjects' skin, as follows: the posterior neck at $\mathrm{C} 5-\mathrm{C} 6,2 \mathrm{~cm}$ from the spinous process; lumbar back at L4-L5, $4 \mathrm{~cm}$ from the spinous process; elbow at the lateral epicondyle vertical to the radius head; posterior knee vertical to fibular head, as illustrated in figure 1. At each site, thickness measurements were taken of the following: the epidermis, dermis, epidermis + dermis, hypodermis, as well as the total skin thickness.

\section{Histology}

This section takes reference from the histological skin data reported by Della Volpe C, et al. [11] in a noteworthy research on 140 skin residues adapted to plastic surgery. In brief, Della Volpe's histological study encompassed two phases. The first was a classic quantitative study consisting of measuring each cutaneous layer and evaluating the elastic density in the superficial dermis. The second was a descriptive histological analysis of each cutaneous area.

\section{Magnetic resonance imaging}

This section is partially based on the forefront MRI skin research conducted by Bittoun J, et al. [12] and Martin, et al., with the latter presented at the 2018 Paris conference of the French Society of Mesotherapy titled "In-vivo MRI study of the skin: toward a new definition of mesotherapy techniques". For comparison purposes, we took into account MRI skin thickness data published by Aubry S, et al. [13] and Sans N, et al., the latter available on the Internet only [14].

For skin conditions, MRI proves challenging due to the tiny structures that are to be visualized. Nevertheless, by increasing either gradient amplitude or duration, skin layers can be visualized with a voxel size of 20 microns. As outlined by Bittoun J, et al., the gradient strength of most commercial systems enables the acquisition of such small voxel sizes [12]. To achieve sufficient sensitivity, the Signal-ToNoise Ratio (SNR) can be increased by minimizing noise with small coils, i.e., superconducting coils that are capable of enhancing the SNR by a factor of $\geq 3$. Using this technology, Aubry S, et al. [13] conducted a study involving 36 healthy subjects who underwent MRI of the face 
and calf. The data clearly revealed good visibility of the epidermis, dermis, and hypodermis, with excellent image quality, few motion artifacts, and a high intra- and inter-observer correlation (kappa coefficient of $\geq 0.84$ ). This paper takes reference from the study's MRI data obtained for the calf only.

\section{Results}

\section{Subject population}

Overall, 80 patients of our daily practice volunteered to participate and all completed the study. The baseline characteristics by gender, age group, and skin type have been listed in table 1. Mean age values by gender and age group have been given in table 2 . The mean ages per age group ranged from 42.3 to 71.2 years, with the youngest subject being 39 and the oldest 82 . The groups' ages were balanced, and their Fitzpatrick skin types were representative of the Geneva general population. In the current research, the US thickness data obtained were compared with histological skin data by Della Volpe C, et al. [11] and with MRI skin thickness data from Aubry S, et al. [13] and Sans $\mathrm{N}$, et al. [14]. These comparative data will be further discussed in the Discussion section.

\section{Ultrasound results}

The different subunits of figure 1 provide an overall view of the anatomical sites where skin thickness measurements were taken using US: A) Posterior neck at C5-C6; B) Lumbar back at L4-L5; C) Lateral epicondyle; D) Posterior knee at fibular head.
The mean data pertaining to US measurements have been summarized by anatomical sites in table 3 . These mean data correspond to the average of 40 measurements pertaining to each single skin layer.

Screen views upon ultrasound measurements for these four sites (A: posterior neck at C5-C6; B: back at L4-L5; C: lateral epicondyle; D: posterior knee) have been provided in figure 2 . Screen views during ultrasound imaging with precise measurements of the different skin layers are given in figure 3 .

As can be seen in table 3, the epidermis displays only slight US thickness variations depending on the anatomical area considered, with mean values varying from 0.07 to $0.10 \mathrm{~mm}$, for the neck/back and epicondyle, respectively. Beneath the epidermis lies the dermis, with mean thickness variations ranging from 1.59 to $3.18 \mathrm{~mm}$ for the neck and back, respectively. For the hypodermis, the mean thickness values range from 0.94 to $3.11 \mathrm{~mm}$ for the epicondyle and back, respectively. For the full skin thickness involving epidermis, dermis, and hypodermis, the lowest mean value was measured for the neck with $3.20 \mathrm{~mm}$, and the highest for the back with $5.83 \mathrm{~mm}$.

Detailed data pertaining to the different skin layers according to the different body areas are provided in Table 4 . The mean skin thickness was the highest at the back, in both men $(9.19 \mathrm{~mm})$ and women $(6.99$ $\mathrm{mm})$; it was the lowest at the epicondyle, again in both men $(2.88 \mathrm{~mm})$ and women $(3.47 \mathrm{~mm})$, with in-between thickness values obtained for the neck and knee.

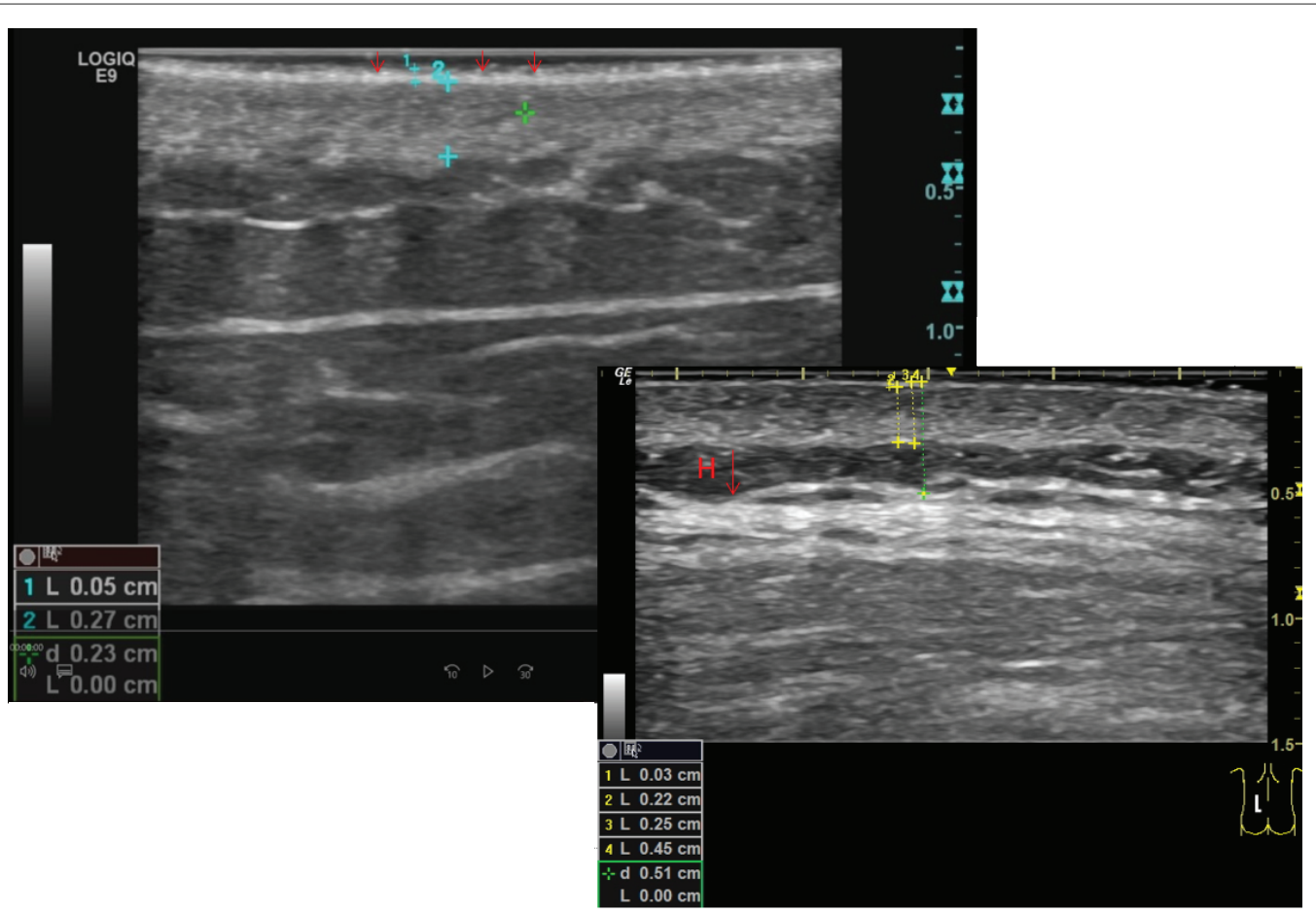

Figure 1: Views focused on measurements of skin thickness.

Above: Red arrow=the "no-touch" technique by using a lot of gel avoiding any contact of the probe with the skin Below: The different skin layers on US view:

$\mathrm{H}=$ Hypodermis or subcutaneous fat.

1=Epidermis, 2=Dermis, included papillary dermis, 3=Epidermis + dermis,

$4=$ Total skin thickness 
Table 1: Demographic data from all subjects.

\begin{tabular}{|c|c|c|c|c|c|c|c|c|c|c|c|c|}
\hline \multicolumn{13}{|c|}{ Women } \\
\hline Age group & $35-45$ years & & & $\begin{array}{l}46-55 \\
\text { years }\end{array}$ & & & $\begin{array}{l}56-65 \\
\text { years }\end{array}$ & & & $>66$ years & & $\begin{array}{c}\text { Mean age } \\
\text { of the } 40 \\
\text { subjects }\end{array}$ \\
\hline Subject & Age in years & $\begin{array}{c}\text { Fitzpatrick } \\
\text { type }\end{array}$ & Subject & $\begin{array}{l}\text { Age in } \\
\text { years }\end{array}$ & $\begin{array}{c}\text { Fitzpatrick } \\
\text { type }\end{array}$ & Subject & $\begin{array}{l}\text { Age in } \\
\text { years }\end{array}$ & $\begin{array}{c}\text { Fitzpatrick } \\
\text { type }\end{array}$ & Subject & $\begin{array}{l}\text { Age in } \\
\text { years }\end{array}$ & $\begin{array}{c}\text { Fitzpatrick } \\
\text { type }\end{array}$ & \\
\hline 1 & 39 & III & 1 & 46 & III & 1 & 56 & V & 1 & 66 & III & \\
\hline 2 & 40 & III & 2 & 48 & II & 2 & 56 & III & 2 & 66 & III & \\
\hline 3 & 40 & II & 3 & 48 & II & 3 & 56 & III & 3 & 67 & IV & \\
\hline 4 & 41 & III & 4 & 48 & II & 4 & 57 & III & 4 & 69 & III & \\
\hline 5 & 42 & IV & 5 & 49 & V & 5 & 57 & II & 5 & 70 & II & \\
\hline 6 & 42 & II & 6 & 53 & III & 6 & 57 & II & 6 & 70 & II & \\
\hline 7 & 44 & II & 7 & 53 & IV & 7 & 58 & IV & 7 & 71 & II & \\
\hline 8 & 44 & II & 8 & 53 & I & 8 & 62 & III & 8 & 73 & III & \\
\hline 9 & 44 & II & 9 & 54 & II & 9 & 63 & II & 9 & 76 & III & \\
\hline 10 & 45 & III & 10 & 55 & III & 10 & 65 & III & 10 & 80 & II & \\
\hline Mean & 42.1 & & Mean & 50.7 & & Mean & 58.7 & & Mean & 70.8 & & 55.6 \\
\hline \multicolumn{13}{|c|}{ MEN } \\
\hline Age group & $35-45$ years & & & $\begin{array}{l}46-55 \\
\text { years }\end{array}$ & & & $\begin{array}{l}56-65 \\
\text { years }\end{array}$ & & & $\begin{array}{c}>66 \\
\text { years }\end{array}$ & & $\begin{array}{c}\text { Mean age } \\
\text { of the } 40 \\
\text { subjects }\end{array}$ \\
\hline Subject & $\begin{array}{l}\text { Age in } \\
\text { years }\end{array}$ & $\begin{array}{c}\text { Fitzpatrick } \\
\text { type }\end{array}$ & Subject & $\begin{array}{l}\text { Age in } \\
\text { years }\end{array}$ & $\begin{array}{c}\text { Fitzpatrick } \\
\text { type }\end{array}$ & Subject & $\begin{array}{l}\text { Age in } \\
\text { years }\end{array}$ & $\begin{array}{c}\text { Fitzpatrick } \\
\text { type }\end{array}$ & Subject & $\begin{array}{l}\text { Age in } \\
\text { years }\end{array}$ & $\begin{array}{c}\text { Fitzpatrick } \\
\text { type }\end{array}$ & \\
\hline 1 & 39 & III & 1 & 46 & IV & 1 & 56 & III & 1 & 66 & V & \\
\hline 2 & 40 & V & 2 & 46 & IV & 2 & 56 & IV & 2 & 66 & III & \\
\hline 3 & 42 & II & 3 & 49 & IV & 3 & 58 & II & 3 & 67 & III & \\
\hline 4 & 44 & II & 4 & 50 & III & 4 & 59 & V & 4 & 69 & III & \\
\hline 5 & 44 & IV & 5 & 50 & III & 5 & 59 & II & 5 & 69 & IV & \\
\hline 6 & 44 & 1 & 6 & 50 & IV & 6 & 61 & IV & 6 & 71 & II & \\
\hline 7 & 45 & II & 7 & 51 & II & 7 & 61 & III & 7 & 73 & II & \\
\hline 8 & 39 & III & 8 & 51 & II & 8 & 61 & IV & 8 & 74 & III & \\
\hline 9 & 45 & IV & 9 & 52 & III & 9 & 62 & IV & 9 & 79 & II & \\
\hline 10 & 43 & II & 10 & 54 & II & 10 & 62 & II & 10 & 82 & II & \\
\hline Mean & 42.5 & & Mean & 49.9 & & Mean & 59.5 & & Mean & 71.6 & & 55.9 \\
\hline
\end{tabular}

Table 2: Mean age of all subjects depending on age groups and gender.

\begin{tabular}{|c|c|c|c|c|}
\hline \multicolumn{5}{|l|}{ Men } \\
\hline Age & $35-45$ years & $46-55$ years & $56-65$ years & $>66$ years \\
\hline Mean age (in years) & 42.1 & 50.7 & 58.7 & 70.8 \\
\hline \multicolumn{5}{|l|}{ Women } \\
\hline Age group & $35-45$ years & $46-55$ years & $56-65$ years & $>66$ years \\
\hline Mean age (in years) & 42.5 & 49.9 & 59.5 & 71.6 \\
\hline \multicolumn{5}{|l|}{ All subjects } \\
\hline Age group & $35-45$ years & $46-55$ years & $56-65$ years & $>66$ years \\
\hline Mean age (in years) & 42.3 & 50.3 & 59.1 & 71.2 \\
\hline
\end{tabular}


Table 3: Mean ultrasound measurements in millimeters $(\mathrm{mm})$ of the examined anatomical areas.

\begin{tabular}{|c|c|c|c|c|}
\hline Measured thickness (mm) & $\begin{array}{c}\text { NECK } \\
\text { (posterior face, C6-C7) }\end{array}$ & $\begin{array}{c}\text { BACK } \\
\text { (at L4-L5) }\end{array}$ & $\begin{array}{c}\text { EPICONDYLE } \\
\text { (lateral forearm) }\end{array}$ & $\begin{array}{c}\text { LEG } \\
\text { (posterior knee)/thigh }\end{array}$ \\
\hline Epidermis & 0.07 & 0.07 & 0.10 & $0.09 / 0.09$ \\
\hline Dermis & 1.59 & 3.18 & 2.98 & $2.01 / 2.00$ \\
\hline Epidermis + dermis & 1.66 & 3.25 & 3.08 & $2.10 / 2.09$ \\
\hline Hypodermis & 1.56 & 3.11 & 0.94 & $3.04 / 1.81$ \\
\hline $\begin{array}{l}\text { Total thickness } \\
\text { Epidermis+dermis+ hypodermis }\end{array}$ & 3.20 & 5.83 & 4.02 & $5.14 / 3.90$ \\
\hline
\end{tabular}

Notes: 1) Highlighted in red color are the measurements in $\mathrm{mm}$ referring to the thigh obtained in Della Volpe's histological study.

2) Each measurement corresponds to the mean value of 40 single measurements per skin layer.

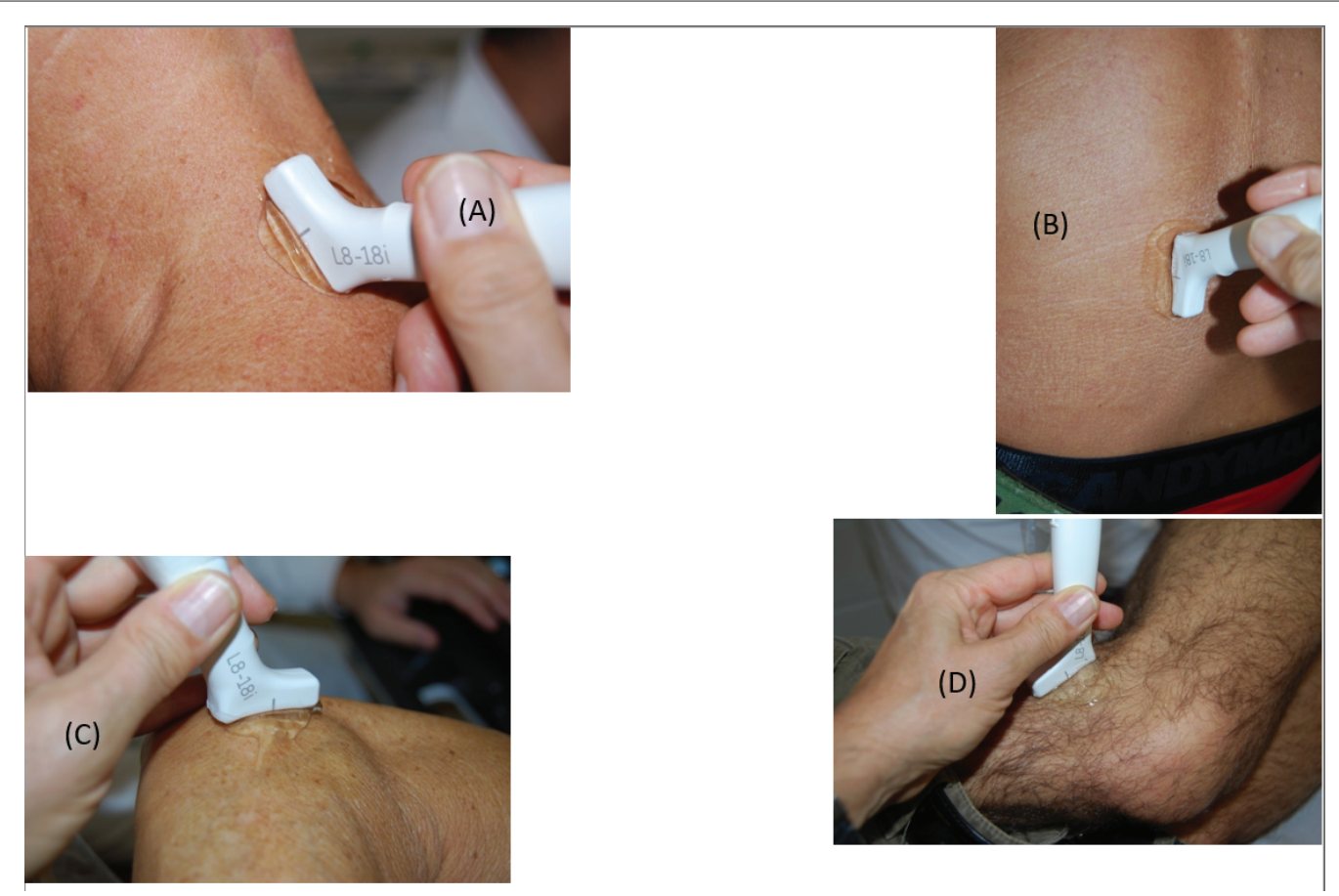

Figure 2: Views during placement of the ultrasound probe for ultrasound measurements.

Above: Left: posterior neck at C5-C6 (A). Right: back at L4-L5 (B).

Below: Left: Lateral Epicondyle (C). Right: Posterior knee vertical to fibular head (D).

\section{Ultrasound versus histology and MRI data}

The ultrasound results, which are deemed to be representative for the Geneva patient population, were compared with the Della Volpe data, acquired using histology and designed for plastic surgery, and the Aubry S, et al. [13] and Sans N, et al. [14] data, obtained via MRI, with their respective data listed in tables 4 and 5 .

In table 4 are listed our US skin thickness data according to gender in comparison with the histological data obtained by Della Volpe with respect to the posterior aspect of the forearm (instead of lateral epicondyle) and lateral aspect of the leg and thigh (instead of the fibular head). In this same table 4 , these data are also compared to the
MRI studies by Aubry S, et al. (lateral calf) and Sans N, et al. (scapula) $[13,14]$.

The comparative areas explored based on histology and MRI measurements are as close as possible to our US-investigated areas. It must be noted that in our study, the US measurement areas were defined well before the idea of comparing them with histology and MRI data derived from the literature arose.

In table 5 are listed our mean US skin thickness data, irrespective of gender, in comparison with the histological data obtained by Della Volpe with respect to the posterior aspect of the forearm (instead of lateral epicondyle) and lateral aspect of the leg and thigh (instead of the 

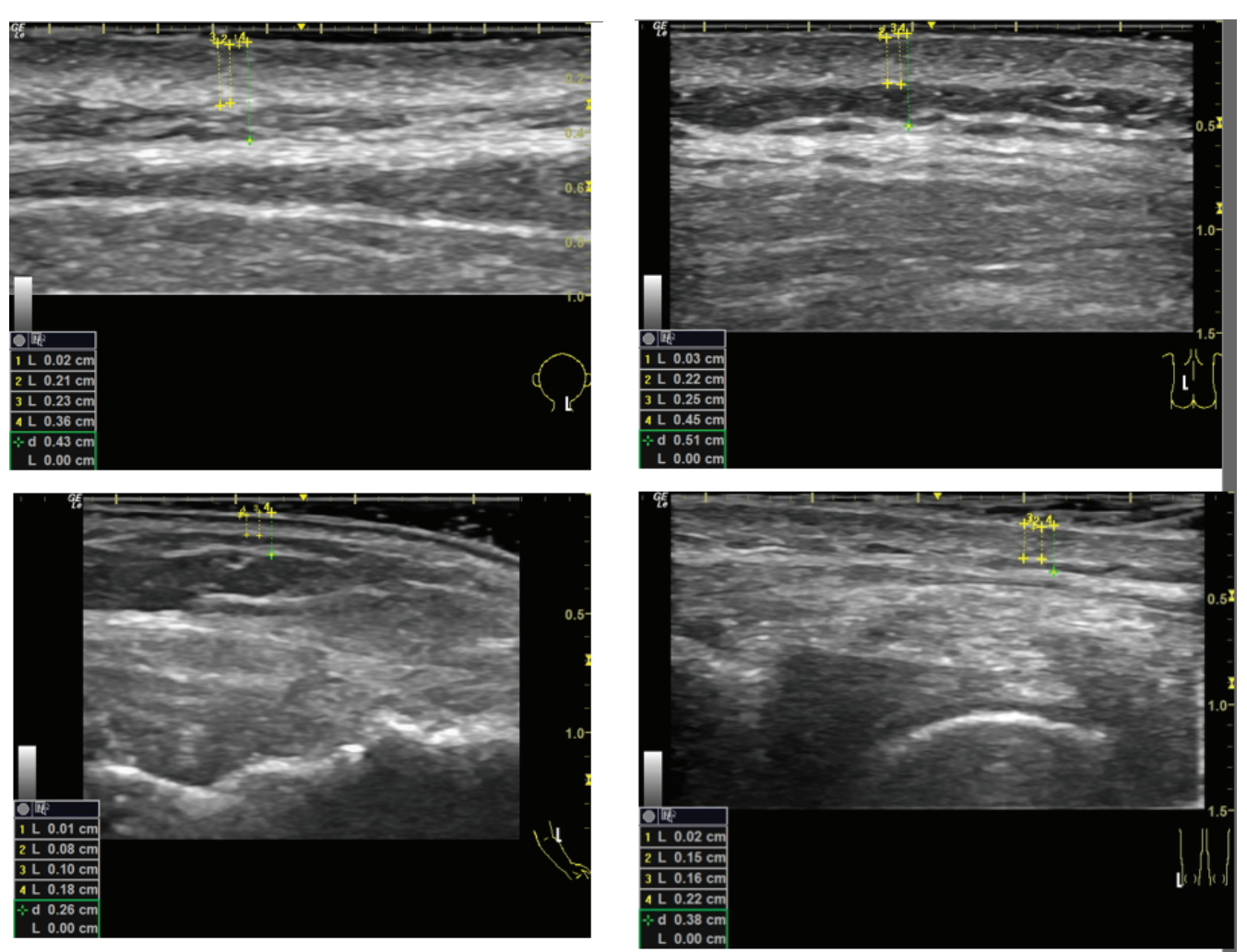

Figure 3: Screen views during ultrasound with measurements.

1=Epidermis thickness; 2=Dermis, including papillary dermis and Sub Epidermal Hypoechoic Band (SEHB); 3=Epidermis + Dermis; 4=Epidermis + Dermis + hypodermis; $d=$ Reticular dermis; $h=$ Hypodermis and Subcutaneous reticular tissue.

Above: Left: posterior neck at C5-C6 (A). Right: back at L4-L5 (B).

Below: Left: Lateral Epicondyle (C). Right: Posterior knee vertical to fibular head (D).

fibular head). These same data are also compared to the MRI studies by Aubry S, et al. (lateral calf) and Sans N, et al. (scapula) [13,14].

It must be mentioned that the number of subjects included in the MRI studies by Aubry S, et al. $(n=36)$ and Sans N, et al. $[13,14](n=31)$ were rather small. Moreover, subjects were also younger in both studies ( 31.4 years and 28 years, respectively), as compared to our own US study ( $\mathrm{n}=80$, age $>55$ years) and to the histology study by Della Volpe as well, with 54 biopsies realized on the upper extremity, 34 on the trunk and 53 on legs and arms.

However, what is even more astonishing and particularly relevant for mesotherapists the following observation: Based on the data collected using the most up-to-date technologies, the skin appears to be much thinner than initially anticipated. The practical impact of this observation will be discussed in the Discussion section.

Under the epidermis lies the papillary dermis. This structure is clearly differentiated from the reticular dermis by the direction of its elastic and collagen fibers. Its mean thickness has been estimated at $200 \mu \mathrm{m}$. The reticular dermis lies underneath the papillary dermis. Its mean thickness is between $300 \mu \mathrm{m}$ and $4 \mathrm{~mm}$, sometimes reaching at up to $10 \mathrm{~mm}$, for instance in the back. [11] It may be arbitrarily divided into equal three thirds consisting of the superficial, mid, and deep dermis, the mean thickness of each layer thus measuring between $100 \mu \mathrm{m}(0.10 \mathrm{~mm})$ and $1.3 \mathrm{~mm}$, depending on the anatomic region.

In the MRI study by Aubry S, et al., it seems that the dermis was only divided into two layers - a superficial dermis and a deep dermis- which were clearly visible on SET 1 and 3D Fiesta MRI sequences [13]. In the calf, the thickness of the superficial and deep dermis was, respectively, $488 \mu \mathrm{m}( \pm 0.49 \mathrm{~mm})$ and $586 \mu \mathrm{m}(5.86 \mathrm{~mm})$.

Comparing the Aubry S, et al. measurements with the histological measurements by Della Volpe leads us to conclude that MRI cannot distinguish the papillary dermis, with this structure apparently included under the term "superficial dermis" in the studies by Aubry S, et al. and Sans N, et al. [13,14].

The epidermis is indeed close to $200 \mu \mathrm{m}$ thick, as described by Della Volpe et al.

If we sum the MRI measurements of the epidermis with those of the "superficial dermis" in the study by Aubry S, et al. or Sans N, et al. $[13,14]$, we obtain the following values: According to Aubry S, et al. [13] the epidermis does measure something like the 200 $\mu \mathrm{m}$ described by Della Volpe C, et al. [11] If we sum the mean histological measurements of the papillary dermis $(150 \mu \mathrm{m})$ and the upper third of the reticular dermis (0.351-1.14 mm, depending on the anatomic area), the results obtained differ from those on MRI. Thus the definitions do not match, even though it must be remembered that the anatomic areas explored, albeit close, were not strictly the same. It must also be borne in mind that the preparatory steps performed on histological slices dry out the material that is to be examined. As conclusion, it appears difficult to accurately compare all the data in the literature depending on the examination techniques used [15]. 
Table 4: Mean ultrasound measurements depending on gender and area, with mean values for women, men, and all, in addition to the histological data by Della Volpe and MRI measurements by Aubry and Sans.

\begin{tabular}{|c|c|c|c|c|c|}
\hline Age group & $39-80$ years & $39-82$ years & Mean age 55.7 years & Della Volpe & Aubry \\
\hline Gender & Woman & Men & $\begin{array}{c}\text { Mean value } \\
\text { (women +men) }\end{array}$ & & \\
\hline Area & & Neck & & & \\
\hline Epidermis & 0.20 & 0.20 & 0.20 & 0.08 & \\
\hline Dermis & 2.02 & 2.54 & 2.28 & 1.59 & \\
\hline Epidermis+ dermis & 2.29 & 2.54 & 2.48 & 1.66 & \\
\hline Hypodermis & 1.96 & 2.59 & 2.28 & 1.54 & \\
\hline Total thickness & 4.24 & 5.40 & 4.82 & 3.20 & \\
\hline Area & & Back & & & Scapula \\
\hline Epidermis & 0.20 & 0.21 & 0.20 & 0.10 & 0.35 \\
\hline Dermis & 2.16 & 2.45 & 2.30 & 3.18 & 2.71 \\
\hline Epidermis + dermis & 2.37 & 2.66 & 2.52 & 3.25 & 3.06 \\
\hline Hypodermis & 6.81 & 4.36 & 5.59 & 2.58 & 2.86 \\
\hline Total thickness & 9.19 & 6.99 & 8.09 & 5.83 & 5.57 \\
\hline Area & & Epicondyle & & Dorsal forearm & \\
\hline Epidermis & 0.20 & 0.21 & 0.20 & 0.12 & \\
\hline Dermis & 1.23 & 1.64 & 1.43 & 1.21 & \\
\hline Epidermis+ dermis & 1.47 & 1.84 & 1.62 & 1.33 & \\
\hline Hypodermis & 1.52 & 1.67 & 1.12 & 2.26 & \\
\hline Total thickness & 2.88 & 3.47 & 3.18 & 4.02 & \\
\hline Area & & Knee & & Pretibial skin & Calf \\
\hline Epidermis & 0.20 & 0.21 & 0.21 & 0.12 & 0.19 \\
\hline Dermis & 1.30 & 1.61 & 1.45 & 1.66 & 1.07 \\
\hline Epidermis+ dermis & 1.50 & 1.76 & 1.63 & 1.76 & 1.26 \\
\hline Hypodermis & 4.07 & 1.78 & 2.92 & 2.92 & 5.45 \\
\hline Total thickness & 5.59 & 3.63 & 4.61 & 4.68 & 6.70 \\
\hline
\end{tabular}

Table 5: Overall mean ultrasound measurements regardless of gender per area, in addition to the histological data by Della Volpe and MRI measurements by Aubry and Sans.

\begin{tabular}{|c|c|c|c|c|c|c|}
\hline & $\begin{array}{l}\text { Epidermis } \\
\text { ( } \mu \mathrm{m})\end{array}$ & $\begin{array}{l}\text { Papillary } \\
\text { dermis }\end{array}$ & Superficial dermis $(\mu \mathrm{m})$ & $\begin{array}{l}\text { Epidermis+ } \\
\text { superficial dermis }(\mu \mathrm{m})\end{array}$ & $\begin{array}{c}\text { Epidermis+papillary dermis+ } \\
\text { superficial reticular dermis }(\mu \mathrm{m})\end{array}$ & $\begin{array}{l}\text { Epidermis+Total } \\
\text { dermis }\end{array}$ \\
\hline & & & AUBRY/SANS & & & AUBRY/SANS \\
\hline Calf & 192 & & 488 & 680 & 680 & 1265 \\
\hline \multirow[t]{2}{*}{ Back } & 350 & & 2710 & 3060 & 3060 & 3060 \\
\hline & & & $\begin{array}{c}\text { DELLA VOLPE } \\
\text { (1/3 of the total dermis) }\end{array}$ & & & DELLA VOLPE \\
\hline Calf & 100 & 200 & 850 & & 1050 & 2100 \\
\hline Back & 100 & 200 & 1060 & & 1360 & 3250 \\
\hline
\end{tabular}

\section{Discussion}

Before further commenting our results, we wish to emphasize that the ultrasound skin thickness measurements from the four different anatomical areas of overall 80 subjects were obtained by a specialist with longstanding expertise in ultrasound technology. When comparing this study's ultrasound measurements with those obtained via histology or MRI, it can be said that the data obtained using these three different tools were similar, yet without being identical.
The differences in skin thickness data depending on the technology used may be partly explained by retraction and dehydration of the skin upon histological preparation. Even if all the placements of the US probe were realized by only one practitioner (PM) and the measurements themselves by the same expert (SV), another possible explanation for the discrepancies in skin thickness identified may be that the ultrasound cursor is less precise compared with both the MRI and histological cursors. It must also be noted that the sample sizes of the MRI studies were rather small, which may lead to biased data. 
Irrespective of the technology applied, there is, however, a key observation that can be drawn based on our study data: The skin is very thin. Based on the four skin thickness datasets obtained, the skin is thinner than initially anticipated, and rather delicate and fragile when intradermal injections are being made. This observation has practical consequences, particularly for mesotherapists, but also for those working within the esthetic field.

With this study, we sought to confirm what we have demonstrated in previous works. The current training methods in view of "mastering" intradermal injections must be completely overhauled, in many different ways, such as: a) the actual injection techniques; b) the competence of the healthcare professional actually performing the injection; c) the requirement of an improved understanding of skin histology. We would like to take this opportunity to remind the readers of the major injections techniques currently used in IDT, and their associated pitfalls. We also have to stress that we must always take account of the indicated injection depths written on the information leaflets of the hyaluronic acid-based fillers.

Intra-epidermal injection: This specific injection technique is performed by using solely three tools, as described by the father of mesotherapy, Dr. Michel Pistor himself, namely the hand, syringe, and needle. When using this technique, the needle is inserted with the bevel directed upwards, barely stirring the thick epidermis layer, causing neither bleeding nor scarring.

Intra-dermal injection: And here comes our first question! What do experts actually mean by superficial dermis? If this refers to the papillary dermis, this would mean that the injection should be to an average depth of 151 to 349 microns. Note that the bevel of a 301/2 $\mathrm{G}$ needle is $1 \mathrm{~mm}$ long. Therefore, even if a jet injector can insert the needle to $0.5 \mathrm{~mm}$ (500 microns), the needle will already be in the reticular dermis. The only possible exception would be if the needle were inserted using a presser-foot type of guiding support at a $30^{\circ}$ angle. Nevertheless, only micro-needling could succeed in injecting a product so superficially.

It is possible that the so-called "nappage" (French for "coating") or superficial intradermal injections in the IDT setting are actually made in the papillary dermis, or even at the very top of the reticular dermis. The light hemorrhagic suffusion that these injections at times provoke actually proves that they have gone past the epidermis and reached capillary networks, at least those found in the papillary dermis (Figure $4)$.

The mathematical formula: "The sine of the needle's penetration angle, in relation to the cutaneous plane, multiplied by the inserted needle length (in $\mathrm{mm}$ ), provides the injection depth obtained (in $\mathrm{mm}$ )". This formula allows for an exact calculation of the injection depth. In IDT, when a classic Lebel needle is employed, being $4 \mathrm{~mm}$ or $3 \mathrm{~mm}$ in length, whether inserted at an angle or, worse still, perpendicular to the skin surface, it will always result in a depth being past the reticular dermis, thus down to the hypodermis (Figure 4). This is due to the pressure exerted by the mesotherapist's hand during the injection, especially if the so-called expert is still in the training process, thus in the middle of the learning curve. We have already reported on the injection depths performed by the most distinguished of our colleagues, and for the most part, not only did the results confirm our beliefs but they even exceeded our expectations [14].

Therefore, the key messages delivered by healthcare professionals during mesotherapy training sessions or esthetic workshops with respect to the skin depths targeted with the different injection techniques must be completely and thoroughly reviewed so that we have a common reference system. In addition, there is a need for a simple, consistent, easily understandable nomenclature to be used in all the mesotherapy research papers. This would enable us to distinguish

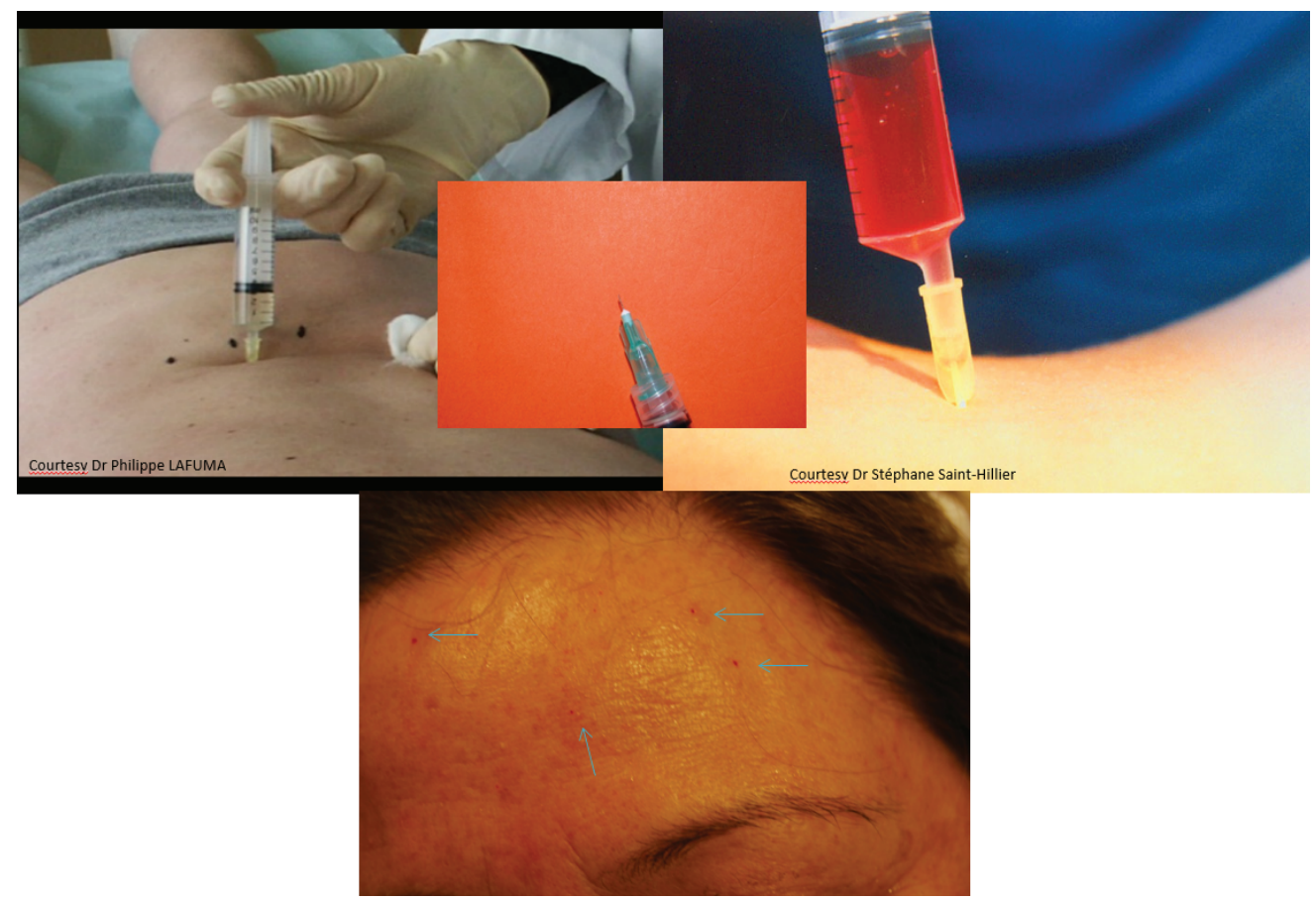

Figure 4: View illustrating different intradermal Mesotherapy injections, using 301/2 G needle and a Lebel needle (bevel $4 \mathrm{~mm}$ long), and a "nappage" or "picotage" injection technique. 
truth from error and knowledge from opinion when talking about results obtained in the Mesotherapy or esthetic research field. There is another point we wish to emphasize in connection with the above remarks. It may be valuable, for beginners, to administer mesotherapy injections (specially the point by point technique) under ultrasound guidance to better ascertain the depth of the injection point. The same can be said for beginners working in the esthetic field. Other issues may, however, arise, such as sterilization concerns or infection risks.

To summarize our previous reports, and in support of our current findings, it is clear and measurable, as well as proven by the collected research data, that most injections are neither confined to the papillary dermis nor possibly the top of the reticular dermis, which is far from being the rule. Based on our evidence, most injections go further down the path to actually reach the hypodermis. Moreover, owing to the rising usefulness of administering intradermal injections, not only in the IDT setting but also in the general medicine field, we will continue our research and come back to you with updated research findings and expanded discussions in due course.

Let us now just mention a few words about our comparison with histologic and MRI papers.

\section{Histology}

The skin areas examined by Della Volpe C, et al. [11] were similar to those investigated by our research team using US, though the Della Volpe team analyzed skin thickness of the posterior aspect of the forearm (instead of lateral epicondyle) and lateral aspect of the leg and thigh (instead of posterior knee at the fibular head). Della Volpe investigated skin residues from roughly similar anatomical areas to ours, with the patient ages not reported.

\section{MRI}

Here, it must be noted that the Aubry S, et al. data [13] considered for comparison pertained to the calf (instead of posterior knee, as in our research) and the Sans N, et al. data [14] to the scapula (instead of the lumbar back, as in our research).

Aubry S, et al. [13] included 36subjects, aged 28.0 years on average, with their MRI calf data considered here to be compared with our posterior knee data. Sans N, et al. [14] included 31 subjects, aged 31.4 on average, with their MRI scapula data considered herein to be compared with our lumbar back data. Our subjects were older, with a mean age of more than 55 years. Therefore, even if the explored were not completely identical, our measurements tended to be in same range.

\section{Conclusion}

Based on this study's findings, it seems warranted that the injection techniques and definitions herein be thoroughly reviewed in order to enable healthcare providers to compare published scientific reports pertaining to this field of growing interest. And what's more, this should enable IDT experts to properly carry out their daily and this, to the greatest benefit of their patients.

\section{References}

1. Pistor M (1976) Abrégé de mésothérapie pratique. Paris: Maloine 149.

2. Lacarrubba F, Tedeschi A, Nardone B, Micali G (2008) Mesotherapy for skin rejuvenation: assessment of the subepidermal lowechogenic band by ultrasound evaluation with cross-sectional B-mode scanning. Dermatol Ther 21: S1-S5.

3. Tedeschi A, Lacarrubba F, Micali G (2015) Mesotherapy with an Intradermal Hyaluronic Acid Formulation for Skin Rejuvenation: An Intrapatient, Placebo-Controlled, Long-Term Trial Using HighFrequency Ultrasound. Aesthetic Plast Surg 39: 129-133.

4. Mammucari M, Gatti A, Maggiori S, Sabato AF (2012) Role of mesotherapy in musculoskeletal pain: opinions from the italian society of mesotherapy. Evid Based Complement Alternat Med 436959.

5. Mammucari M, Gatti A, Maggiori S, Bartoletti CA, Sabato AF (2011) Mesotherapy, definition, rationale and clinical role: a consensus report from the Italian Society of Mesotherapy. Eur Rev Med Pharmacol Sci 15: 682-694.

6. Thierree RA, Mrejen D (1985) Microcirculation, mesotherapy, and thermography. J Mal Vasc 10: 207-208.

7. Micheels P, Sarazin D, Besse S, Sundaram H, Flynn TC (2013) A blanching technique for intradermal injection of the hyaluronic acid Belotero. Plast Reconstr Surg 132: 59S-68S.

8. Tran C, Carraux P, Micheels P, Kaya G, Salomon D (2014) In vivo bio-integration of three hyaluronic acid fillers in human skin: a histological study. Dermatology 228: 47-54.

9. Micheels P, Besse S, Flynn TC, et al. (2014) Etude échographique comparative de la diffusion de 3 gels d'acide hyaluronique de comblement de rides "FDA approved", lors d'injections intradermiques superficielles et moyennes. J Med Esthet Chir Derm 162: 95-100.

10. Gupta V, Sharma VK (2019) Skin typing: Fitzpatrick grading and others. Clin Dermatol 37: 430-436.

11. Della Volpe C, Andrac L, Casanova D, Legré R, Magalon G (2012) Skin diversity: histological study of 140 skin residues, adapted to plastic surgery. Ann Chir Plast Esthet 57: 423-449.

12. Bittoun J, Querleux B, Darasse L (2006) Advances in MR imaging of skin. NMR Biomed 19: 723-730.

13. Aubry S, Casile C, Humbert P, Jehl J, Vidal C, et al. (2009) Feasibility study of 3-T MR imaging of the skin. Eur Radiol 19: 1595-1603.

14. Sans N, Lalande C, Assouère MN, Loustau O, Despeyroux Ewers ML, et al. (2004) Anatomie de la peau en Irm.

15. Micheels P, Goodman L (2018) Injection Depth in Intradermal Therapy: Update and Correction of Published Data. J Drugs Dermatol 17: 88-96. 